\title{
Characterization of Metal Oxide-Based Gas Nanosensors and Microsensors Fabricated via Local Anodic Oxidation Using Atomic Force Microscopy
}

\author{
Bráulio S. Archanjo, ${ }^{1}$ Pablo F. Siles, ${ }^{2}$ Camilla K. B. Q. M. Oliveira, ${ }^{3}$ \\ Daniel L. Baptista, ${ }^{4}$ and Bernardo R. A. Neves ${ }^{3}$ \\ ${ }^{1}$ Divisão de Metrologia de Materiais, Instituto Nacional de Metrologia (INMETRO), Qualidade e Tecnologia, \\ 25250-020 Duque de Caxias, RJ, Brazil \\ ${ }^{2}$ Laboratório Nacional de Luz Síncrotron, Caixa Postal 6192, 13083-970 Campinas, SP, Brazil \\ ${ }^{3}$ Departamento de Física, Universidade Federal de Minas Gerais, 30123-970 Belo Horizonte, MG, Brazil \\ ${ }^{4}$ Instituto de Física, PPGMicro, Universidade Federal do Rio Grande do Sul, 91501-970 Porto Alegre, RS, Brazil \\ Correspondence should be addressed to Bráulio S. Archanjo; bsarchanjo@inmetro.gov.br
}

Received 27 May 2013; Accepted 13 August 2013

Academic Editor: Bin Zhang

Copyright (C) 2013 Bráulio S. Archanjo et al. This is an open access article distributed under the Creative Commons Attribution License, which permits unrestricted use, distribution, and reproduction in any medium, provided the original work is properly cited.

\begin{abstract}
This work reports on nanoscale and microscale metal oxide gas sensors, consisting of metal-semiconductor-metal barriers designed via scanning probe microscopy. Two distinct metal oxides, molybdenum and titanium oxides, were tested at different temperatures using $\mathrm{CO}_{2}$ and $\mathrm{H}_{2}$ as test gases. Sensitivities down to ppm levels are demonstrated, and the influence of dry and humid working atmospheres on these metal oxide conductivities was studied. Furthermore, the activation energy was evaluated and analyzed within working sensor temperature range. Finally, full morphological, chemical, and structural analyses of the oxides composites are provided allowing their identification as $\mathrm{MoO}_{3}$ and $\mathrm{TiO}_{2-x}$.
\end{abstract}

\section{Introduction}

Industrial and scientific communities share an increasing interest in metal oxide materials due to their wide applications to gas sensing, which already resulted in several commercial products [1]. Metal oxide sensors can operate in landfill toxic gas detections [2] and automotive industry for combustion emission control [3], as well as in many other industrial fields [1]. Although these metal oxide gas sensors have considerable applications, some problems related to reproducibility, stability sensitivity, and selectivity must be overcome. Therefore, by studying and enhancing the properties of metal oxide gas sensors, their utilities will also improve accordingly [1].

In most cases, the physical principle of the sensor is simply based on conductivity variations when different gas species interact on the sensor surface. These gas-sensor interactions extract or inject electrons or holes in the semiconductor structure. Such charge exchange between the gas species and the metal oxide semiconductor can be described as reversible chemisorptions and/or physisorptions [1]. However, some undesirable irreversible chemical reactions can also occur both on the oxide and electrical contacts, changing their structures and transforming them into another compound $[1,4-6]$.

In order to map out the best solution for each gas sensing application, many studies are found in the literature [1-22]. Most of them are empirical investigations, where a huge variety of materials and preparation forms including ceramic, thick and thin films, sintered powders, and nanostructures are investigated. In each case, different deposition techniques are employed, both for the active region of the sensor and their electrical contacts [1-22].

Recent advances in microfabrication techniques have opened the possibility of fabrication and integration of metal oxide sensors in the nanoscale. A well-known example is the growth and manipulation of individual, or multiple, metal oxide nanowires and their use as gas sensors [23-28]. In 
the past few years, new gas microsensors and nanosensors fabrication processes have been demonstrated by adding extra steps to microfabrication technologies, either by AFM or needle manipulation, in which drops of metal oxide precursors are placed onto microgap electrodes [29-32].

The Local Anodic Oxidation (LAO) process, due to an applied bias between the scanning probe microscopy (SPM) tip and sample, was first demonstrated in 1990, employing the scanning tunneling microscopy technique [33]. In 1993, the process was also successfully applied using atomic force microscopy (AFM) [34]. In 1995, also via LAO process, a sub-10-nanometer metal oxide device was fabricated [35] and, in 1996, a single electron transistor operating at room temperature was built using the LAO process [36]. As it can be seen in the literature, since then, some other devices were proposed and built using the LAO process [37-39].

In this work, chemical and structural characterizations via high-resolution scanning and transmission electron microscopy (HR-STEM and HR-TEM) are presented as well as a discussion about the proposed fabrication method for metal oxide nanosensors [40, 41] and microsensors [41] using SPM-based LAO technique. Through electron energy loss spectroscopy at high-resolution energy (around $0.3 \mathrm{eV}$ ), a detailed chemical analysis of the devices is also presented. This simple and reproducible fabrication method can be summarized in two steps: (i) conventional optical lithography is implemented to define a micron-scale, thin metallic track with macroscopic electrical contacts; and (ii) an LAO process is used to design nano- or microscaled oxide patterns on the metal films, defining a metal oxide interface which constitutes the active region of the sensor. In order to demonstrate the viability of this methodology, two metals are used to fabricate molybdenum oxide [41] and titanium oxide [40, 41], nanosensors and microsensors, whose performance is evaluated by monitoring variations on their electrical conductivity, using two distinct gases: $\mathrm{CO}_{2}$ and $\mathrm{H}_{2}$ (reducing test gas) under commercial $\mathrm{N}_{2}$ (dry air) atmosphere at different temperatures. In addition, the activation energy of these sensors is investigated through the Arrhenius plots $[1,42]$ and $I(V)$ curves in the presence of humidity different atmospheres. Therefore, sensors performance is evaluated considering, their durability, sensitivity to each gas, influence of sensor size, and temperature.

\section{Materials and Methods}

In the present work, both AFM imaging and LAO are accomplished using an NT-MDT Solver Pro SPM or a veeco instruments nanoscope IV multimode SPM operating in intermittent contact mode. Silicon probes, coated with conductive diamond films (DCP11 series, from NT-MDT, with a resonant frequency of $\sim 150 \mathrm{kHz}$ and a force constant of $\sim 5 \mathrm{~N} / \mathrm{m}$ ), are employed due to their higher conductivity and greater resistance to oxidation than those of bare silicon probes. In order to optimize it, the LAO process is performed under a relative humidity of $60 \%$, controlled by a homemade system. Also, the tapping mode is employed, and, during the oxidation, the oscillation amplitude is reduced to $10 \%$ of the free oscillation amplitude. Each sensor is tested in a homemade apparatus, where the sample temperature can be varied from room temperature up to $400^{\circ} \mathrm{C}$, equipped with mass flux control valves. During each measurement, both the total gas flux and temperature are kept constant. Performance of the devices is quantified via current measurements using a Keithley electrometer model 6517A.

The main drawbacks for deep chemical and structural investigation of LAO metal oxides are related to the nanometer scale of the defined structures, preventing their analysis via conventional techniques, or even transmission electron microscopy (TEM) analysis, due to the complexity of the conventional sample preparation for cross-section observation. In this direction, the focused ion beam (FIB) technique has recently opened a route for a detailed study of such nanostructures [39]. A comprehensive assessment of nanometer scale LAO metal oxides is here presented with the help of high-resolution TEM and scanning TEM (HRTEM and HR-STEM, resp.), coupled with electron energy loss spectroscopy (EELS). These analyses were carried out in an FEI Titan 80/300 apparatus equipped with a Gatan Tridiem imaging filter.

\section{Microsensors and Nanosensors Fabrication}

The fabrication process initiates with a conventional photolithography process, where metal ( $\mathrm{Ti}$ or Mo) tracks, a few microns wide and hundreds of microns long, are defined simultaneously with their macroscopic electrical contacts on an insulating silicon dioxide substrate. During this procedure, titanium, or molybdenum, (99.99\% purity) is deposited either by thermal evaporation or by RF sputtering, with a film thickness varying from $5 \mathrm{~nm}$ up to $20 \mathrm{~nm}$.

LAO routes are employed in the second fabrication step, which enables the definition of nano- or micron- sized metal oxide regions, constituting the active region of the sensor. In this work, the LAO routes are SPM-based; that is, the metal oxide is formed through an electrochemical reaction in the region below a properly biased AFM tip [33-41]. In the process, nominally tip bias (VT) ranges from $1 \mathrm{~V}$ up to $100 \mathrm{~V}$ and scan speeds vary from $0.1 \mu \mathrm{m} / \mathrm{s}$ to as high as $10 \mu \mathrm{m} / \mathrm{s}$, allowing a high control of both size and geometry of the oxide pattern and producing active regions down to the nanoscale [33-41, 43, 44].

Figure 1 shows topographic AFM images of typical metaloxide nanosensors and microsensors made out of $\mathrm{Mo} / \mathrm{MoO}_{x}$ (light brown parts in Figures 1(a), 1(b), 1(c), and 1(d)) and Ti/ $\mathrm{TiO}_{x}$ (yellow parts in Figures 1(e), 1(f), 1(g), and 1(h)) systems. In these Figures, thin metal tracks $(20 \mathrm{~nm}$ for Mo and $8 \mathrm{~nm}$ for $\mathrm{Ti}$ ) are visible atop the $\mathrm{SiO}_{x}$ substrates. The oxidized regions are the active regions of the sensor and average thickness of $12 \mathrm{~nm}$ and $60 \mathrm{~nm}$ is observed for titanium oxide and molybdenum oxide, respectively. The more controlled LAO route (low VT and low speed) produces a uniform nanoscale oxide line crossing the entire width of the metal track (Figures 1(b), 1(e), and 1(h)) [40, 41], whereas a fast LAO route yields a less uniform oxide (Figures 1(a), 1(c), 1(d), 1(f), and $1(\mathrm{~g})$ ). Nevertheless, such morphological variation has no significant effect on device performance; that is, similar-sized devices (smooth or rough) present similar sensing responses. 


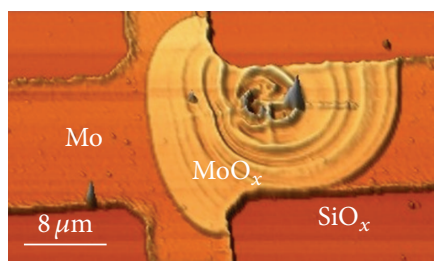

(a)

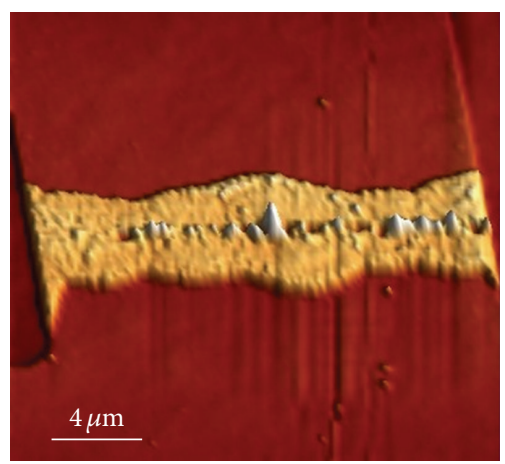

(c)

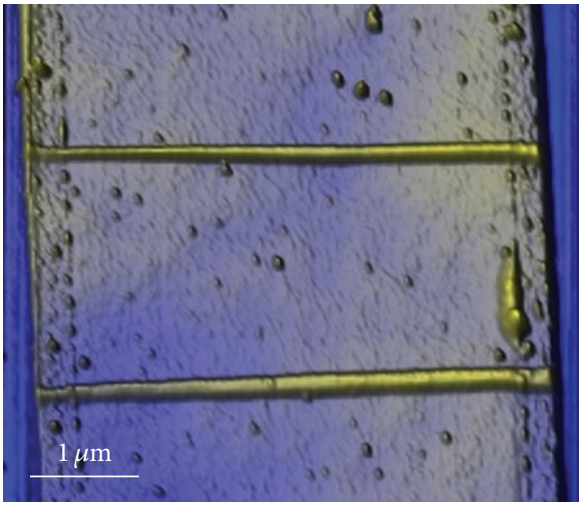

(e)

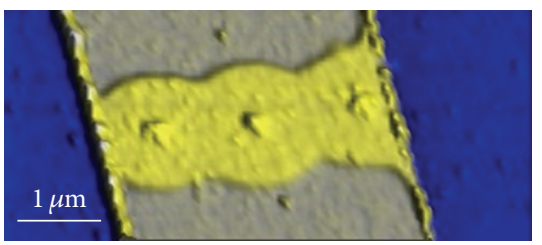

(g)

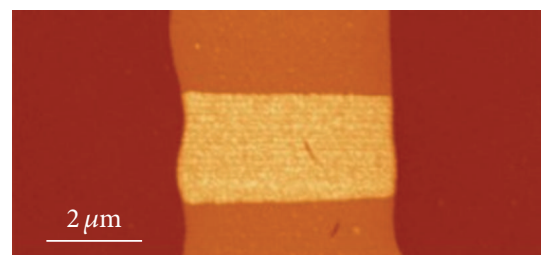

(b)

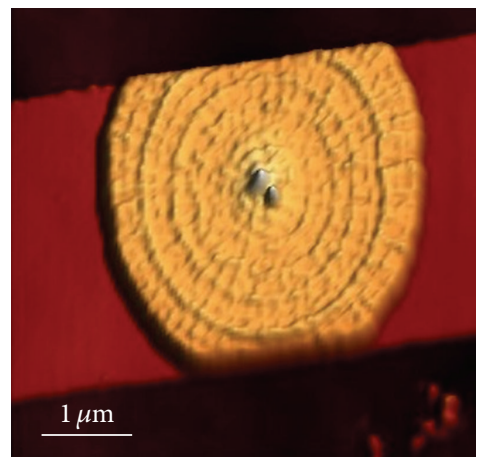

(d)

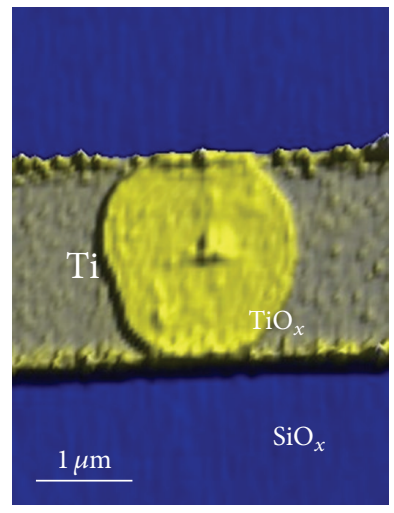

(f)

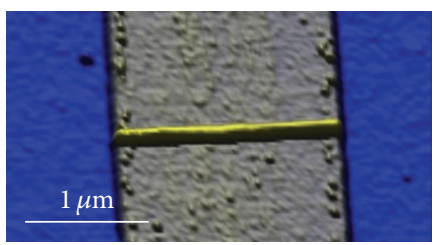

(h)

FIgURE 1: (Color online) Topographic AFM images of different nanosensors and microsensors fabricated via LAO routes. (a) A roundedshaped Mo oxide region (light brown) is formed in the Mo track. (b) Image showing several consecutive oxide lines forming a micron-sized active region of the Mo oxide sensor. (c) Micron-sized single line sensor active region of Mo oxide. (d) A microsensor rounded-shaped Mo oxide region is formed in the center of the Mo track. (e) Image showing two consecutive active regions of a Ti oxide (yellow) nanosensor separated by several hundreds of nanometers. (f) Microsensor Ti oxide produced with the AFM tip at rest. (g) Image of a Ti oxide microsensor fabricated via three consecutive oxidation spots. (h) Nanowire-type Ti oxide region is formed in a Ti track.

Figures 1(b) and 1(c) show two typical AFM images after applying the LAO process in Mo, where in the first case, many oxide lines are built side-by-side using a VT of $10 \mathrm{~V}$ and a tip velocity of $10 \mu \mathrm{m} / \mathrm{s}$. In the second case, the tip velocity is reduced down to $0.1 \mu \mathrm{m} / \mathrm{s}$ and the VT is increased up to $15 \mathrm{~V}$; therefore, only one scan is sufficient to fabricate a microsensor, since considerable lateral oxide growth takes place.
When identical LAO parameters are applied in Ti and Mo, the titanium oxide presents smaller lateral oxide diffusion and smothers surface. As a consequence, if the same titanium oxide and molybdenum oxide dimensions are required, a higher VT and a lower tip velocity are required during the LAO fabrication of Ti-based sensors (or the tip rest time must be longer when a round shape is required). Figure 1(e) 
shows the result of making two separated oxide lines, and, in Figure 1(h), only one line (nanowire-type sensor) is built. Figure 1(g) illustrates the result after applying three highvoltage $\mathrm{LAO}$ processes, side by side, in the same Ti track, and Figure 1(f) exemplifies the results of only one round-shape sensor in the center of the metallic track.

It is interesting to notice here that the direct fabrication of the sensor active region in a metallic track presents a promising technological application. Actually, this two-step sequence, photolithography and LAO route, allows the fabrication of nanosensors and microsensors of a variety of metal oxides, eliminating many time-consuming steps, which are typical to nanowire-based sensor fabrication, such as localization, manipulation, and contacting of the active region. Essentially, the LAO route process creates additional possibilities in device manufacturing.

\section{Results and Discussion}

4.1. Chemical and Structural Analyses of the Metal Oxides. In order to fabricate sensor devices with reproducible performance, it is crucial to identify the stoichiometry of the oxide structure. Nevertheless, due to the small oxide size and the presence of the precursor metal in the surrounding track, direct measurements using conventional techniques (X-ray photo-electron spectroscopy or X-ray diffraction) did not produce conclusive results. However, assuming that the transformation of the metal into oxide is homogeneous and that the volume expansion only occurs in the vertical direction, an estimation of oxide stoichiometry can be made comparing the thickness of the oxide and metal layers [44].

In order to assess the oxide depth (inside the metal track), the electrical resistance is monitored before and after the oxidation process. Hence, the metal track electrical resistance increases from a few $\mathrm{k} \Omega$ up to several $\mathrm{M} \Omega$, or even $\mathrm{G} \Omega$, when the metal is completely oxidized. On the other hand, if the oxide depth is smaller than the metal layer thickness and does not reach at the silicon oxide, the electrical resistance does not reach several $\mathrm{M} \Omega$.

When analyzing the thickness ratio between the titanium oxide and Ti layers, it is possible to observe a variation from 1.2 to 1.8 , depending mostly on the metal thickness (the thinner the Ti layer, the lower the thickness ratio). A possible origin of such variation is that, in thinner metal films, the effective metal thickness is smaller, since the native oxide layer and the organic contamination due to the optical lithography are independent of the metal thickness and, thus, have a large contribution to the total measured thickness. According to Dengfeng et al. and references therein [44], if a pure $\mathrm{TiO}_{2}$ layer is formed, the ratio would be 1.85 and the formation of a pure TiO layer gives a ratio of 1.45. Here, for a $10 \mathrm{~nm}$ Ti layer (where the native Ti oxide and contamination layers are less significant), an oxide height of $18 \mathrm{~nm}$ could be obtained. Therefore, the stoichiometry of titanium oxide, $\mathrm{TiO}_{2-x}$, is mostly $x=0$.

In order to further discuss the chemical and structural characteristics of the LAO SPM-based metal oxides, we have used high-resolution scanning and transmission electron microscopy (HR-STEM and HR-TEM). Spatially-resolved monochromated electron energy-loss spectroscopy (EELS) has been also performed in the STEM mode. Cross-sections of LAO oxide tracks were carefully prepared using focused ion beam (FIB) TEM sample preparation methods.

Scanning electron micrographs of the LAO titanium oxide tracks before FIB TEM sample preparation are shown in Figure 2(a). The tracks after platinum protective layer deposition are shown in Figure 2(b). The three thin Pt lines perpendicular to the conventional thick one were used to allow the localization of the oxide tracks in the final thinning and cleaning during the FIB processing. In Figures 2(c) and 2(d), we show high-angle annular dark field (HAADF) STEM images of one metal oxide track. The brighter regions represent higher density and/or higher average atomic number $(\mathrm{Z})$ zones. Thus, the protective Pt layer appears as the brightest layer on the top of Figure 2(c). The $\mathrm{SiO}_{2}$ substrate is observed as a dark layer on the bottom, followed by the Ti film at the center and the titanium oxide track just above. The interface between the metallic and oxidized Ti layers is shown in higher magnification in Figure 2(d). Lattice-plane structures are clearly observable even in the titanium oxide region (darker contrast). Figures 2(e) and 2(f) show HR-TEM images of the same interface region. It is possible to observe a highly crystalline Ti grain zone and a less-crystalline oxidized one. This result can be confirmed comparing the Fast Fourier Transform (FFT) of the top and bottom parts of Figure 2(f), which are shown, respectively, in Figures $2(\mathrm{~g})$ and $2(\mathrm{~h})$. In Figure $2(\mathrm{~g})$ we observe the periodicities of $2.2,2.4$, and $2.6 \AA$ from metallic Ti in hexagonal close-packed (HCP) structure. In Figure 2(h), from the titanium oxide, we measured the periodicities of 2.2, 2.4, and $2.3 \AA$, which are present in both rutile and anatase phases. Additionally, blurred low frequency spots, roughly corresponding to $3.5 \AA$ planes, suggest the presence of an anatase nanocrystalline phase. For easily viewing these spots are circled. After applying a bypass filter on a four-circled area, the image in Figure 2(i) is obtained. These results show nanocrystallites around $3 \mathrm{~nm}$.

In order to complement this result, we performed localized STEM-EELS analyses of both metallic and oxidized Ti. In Figures 3(a) and 3(b) we show, respectively, the Ti $\mathrm{L}_{2 ; 3}$ and $\mathrm{O}$ $\mathrm{K}$ core-loss spectra. As expected, the oxygen signal is present for the oxidized Ti layer, whereas there is no oxygen signal for metallic Ti. From the Ti $\mathrm{L}_{2: 3}$ core-loss curves, a shift for large energies of about $1 \mathrm{eV}$ for the titanium oxide is observed when compared to the metallic Ti spectrum. Comparing the obtained Ti $\mathrm{L}_{2 ; 3}$ core-loss spectrum for titanium oxide with others published in the literature $[39,45,46]$, we confirm that the titanium oxide is nanocrystalline, since it shows broad EELS signals with a large superposition. Also, the signal is very similar to reduced $\mathrm{TiO}_{2-x}$ present in memristive devices [47], suggesting an identification of our grown titanium oxide as a nanocrystalline anatase rich in oxygen vacancies or better anatase $\mathrm{TiO}_{2-x}$.

For the case of Mo oxide, water solubility is observed, which suggests an exact $\mathrm{MoO}_{3}$ stoichiometry [48]. Therefore, in order to complement the metal oxide/metal thickness ratio study, some oxide thickness measurements were carried out via AFM topography analysis (before and after washing out the oxide layer in deionized water for 2 minutes in ultrasonic 


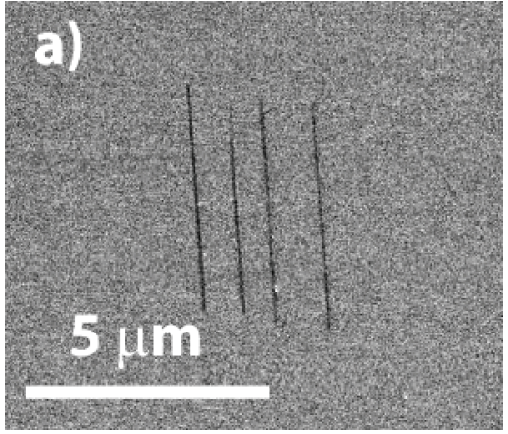

(a)

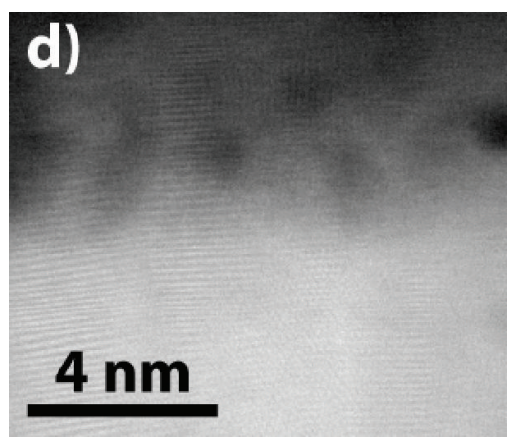

(d)

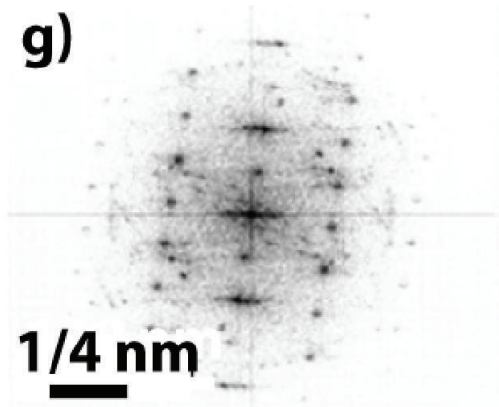

(g)

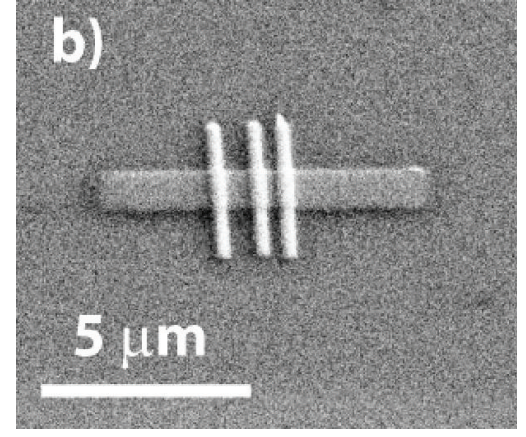

(b)

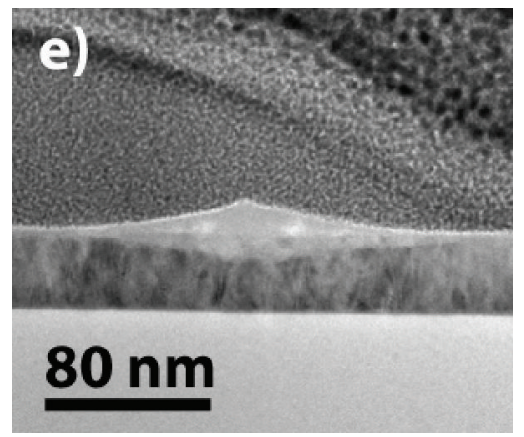

(e)

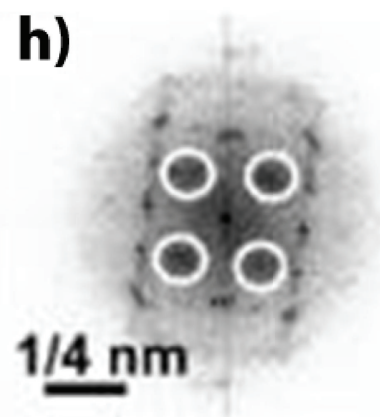

(h)

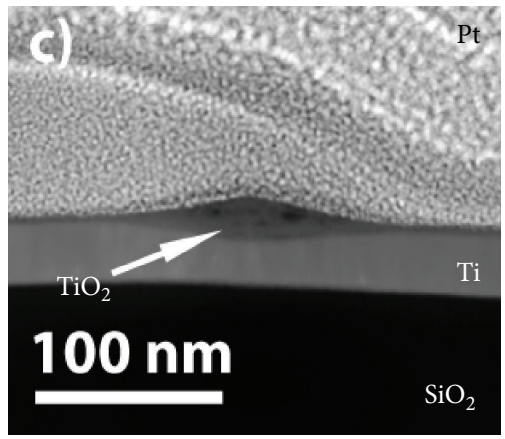

(c)

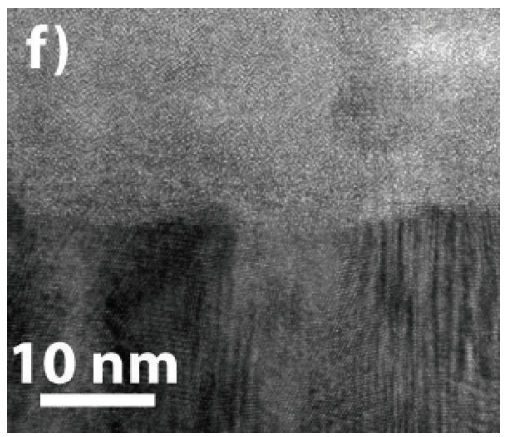

(f)

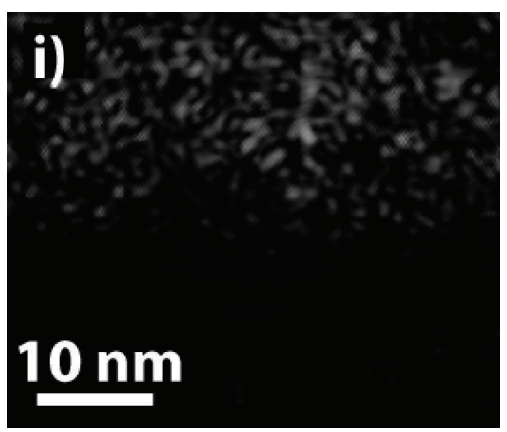

(i)

FIGURE 2: Images of high-resolution electron microscopy and related techniques of the titanium oxide line sensor active region. (a) SEM image of four Ti oxide lines. (b) SEM image of the same region as in Figure 2(a) after Pt deposition of the protective layer on the top of three lines. (c) HAADAF image in STEM mode of the lamella showing a cross-section of the titanium oxide line. (d) HAADAF high-resolution image of the bottom metallic-oxide interface. (e) TEM image of the same region showed in Figure 2(d). (g) High-resolution TEM image of the same region showed in Figure 2(d). (f) FFT image of the Ti in the most lower part of Figure 2(f). (h) FFT image of the Ti oxide in the upper part of Figure 2(f). (i) HRTEM image showing the titanium oxide nanocrystals after applying a bypass filter in FFT of the four spots circled in Figure 2(h).

bath). Figure 4 shows an AFM topographic image of the oxidized regions before (Figure 4(a)) and after (Figure 4(b)) washing out the oxide. A set of experimental data is plotted in Figure 4(c). The angular coefficient of the linear fit leads to a thickness ratio of $3.2 \pm 0.1$, which, indeed, corresponds to $\mathrm{MoO}_{3}$ compound formation during LAO application in Mo.

Aiming to endorse the previous result, HRTEM and STEM-EELS techniques were also performed. Figures 5(a) and 5(b) show two electron micrographs of oxidized Mo tracks before and after platinum protective layer deposition. The cross-section sample was prepared through FIB and analyzed using STEM (Figure 5(c)) and TEM (Figures 5(d) and 5(e)). In Figure 5(c), the HAADF-STEM image of the cross-sectioned Mo oxide track is observed. The brighter layer located at the middle of the image represents the Mo film, followed by the Mo oxide track just above and a granular region corresponding to the $\mathrm{Pt}$ protective layer. The $\mathrm{SiO}_{2}$ substrate layer is represented by the darkest region at the bottom. In Figures 5(d) and 5(e) we show TEM images of the same region (reverse contrast compared to HAADF-STEM). The TEM analyses do not show evidence of Mo crystalline structures. EELS spectra of the metallic and oxidized Mo regions are presented in Figure 5(f). The $\mathrm{Mo} \mathrm{M}_{3}$ edge is observed for both Mo phases, whereas the $\mathrm{O} \mathrm{K}$ edge is 


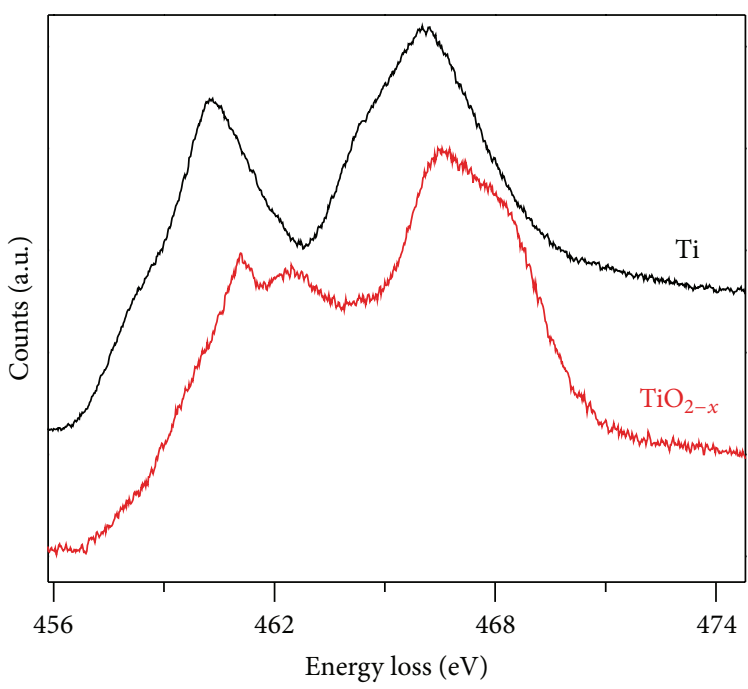

(a)

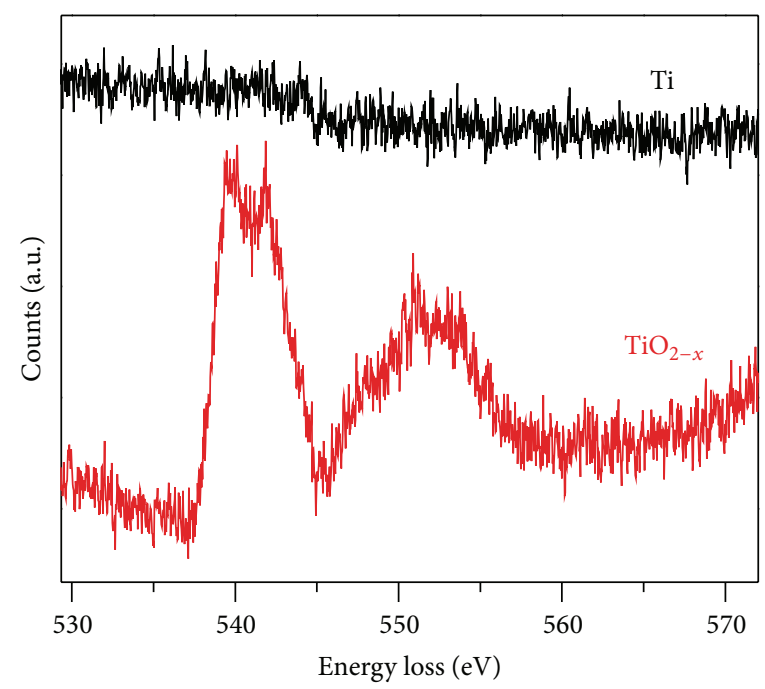

(b)

Figure 3: (Color online) EELS spectra of Ti (black lines) and Ti oxide (red lines) for (a) $\mathrm{Ti}_{2 ; 3}$ core-loss and (b) O K core-loss.

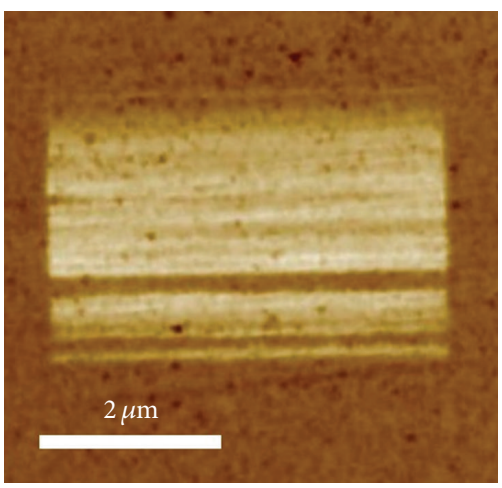

(a)

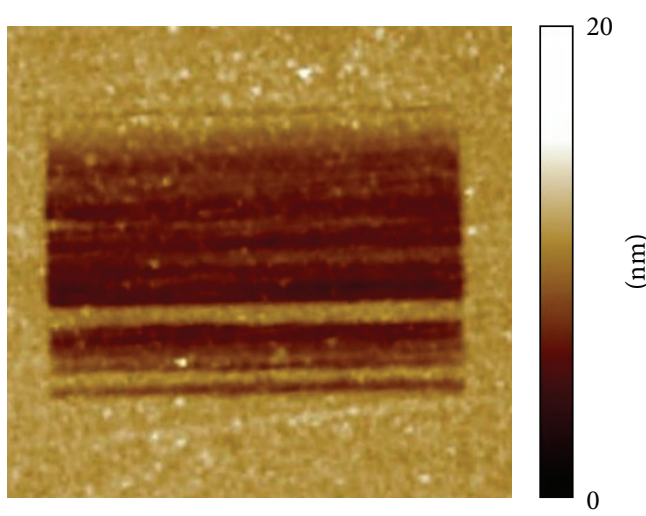

(b)

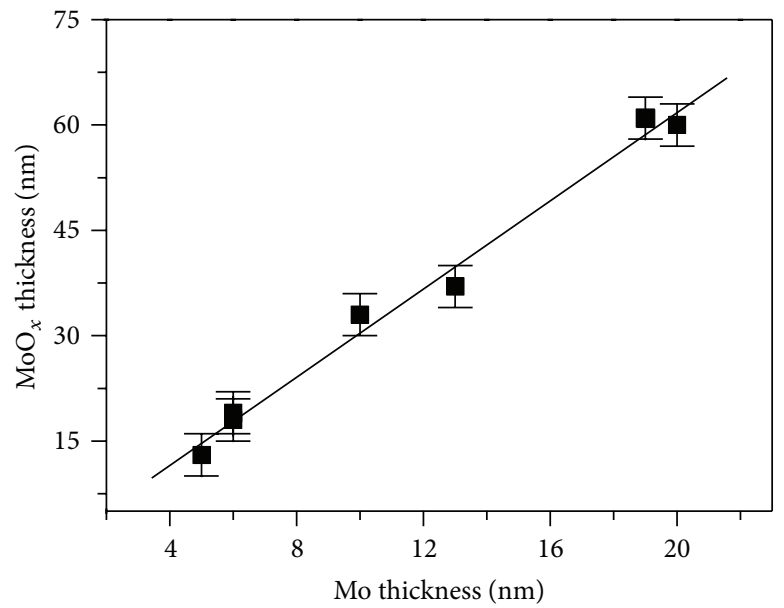

(c)

FIgURE 4: (Color online) Topographic AFM images of square-like oxidized regions via LAO process in Mo film, (a) just after applying LAO process and (b) subsequent to washing out the oxide in deionized water. (c) A graph showing Mo oxide versus Mo thicknesses revealing the ratio $\mathrm{MoO}_{x} / \mathrm{Mo}$ as $3.2 \pm 0.1$. 


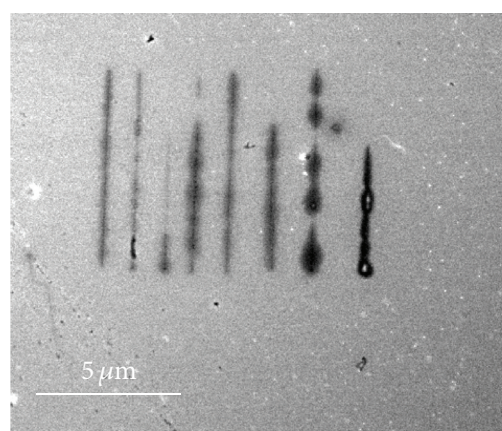

(a)

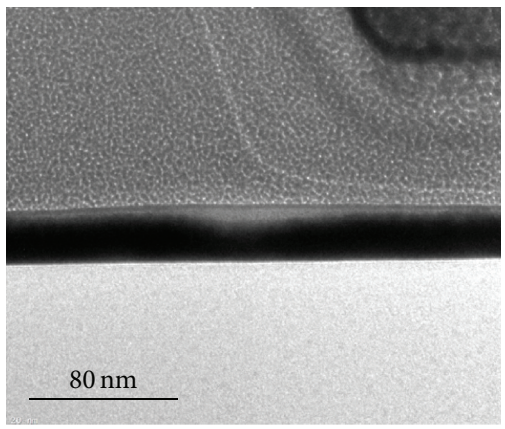

(d)

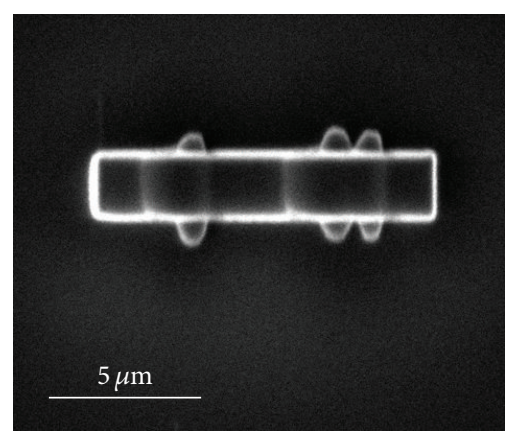

(b)

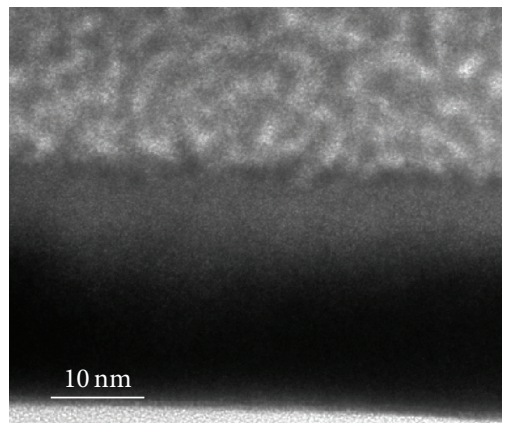

(e)

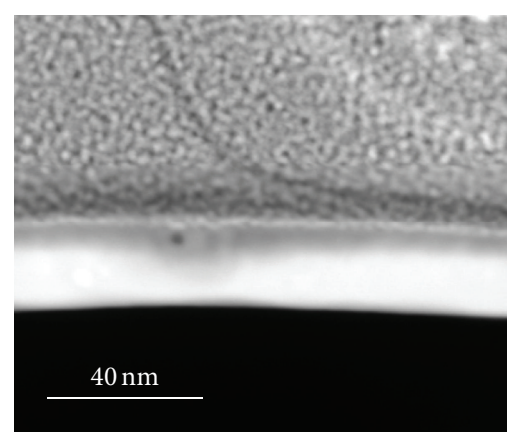

(c)

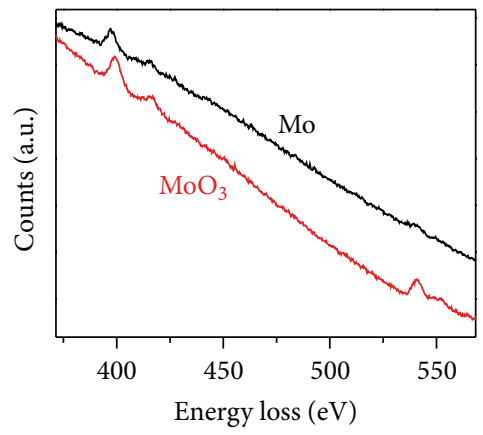

(f)

FIgure 5: (Color online) (a) SEM image of Mo oxide lines. (b) SEM image of the same region as in (a) after Pt deposition of the protective layer on the top of three lines. (c) TEM image of the lamella showing a cross-section of the Mo oxide line. (d) HAADAF image in STEM mode of the same region showed in (c). (e) HAADAF high-resolution image of the Mo and Mo oxide. (f) EELS spectra containing both the $\mathrm{O} \mathrm{K}$ core-loss (right) and the $\mathrm{Mo} \mathrm{M}_{3}$ core-loss (left) of Mo (black line) and $\mathrm{MoO}_{3}$ (red line).

presented only for the oxide one, as expected. Although it is possible to identify the oxide nature of the oxidized Mo track, we were not able to infer on its structure and stoichiometry. As suggested in [49], the exposition of Mo oxide samples to electron irradiation may induce phase transformation from $\mathrm{MoO}_{3}$ to $\mathrm{MoO}_{2}$ and MoO. In our case, both TEM analysis and FIB-TEM sample preparation may induce chemical and structural changes on pristine samples. An amorphous Mo oxide phase may be formed. Further experiments using lowvoltage TEM and convectional TEM sample preparation could be performed to avoid any phase transformation.

4.2. Sensor Properties and Characteristics. The response of each sensor is analyzed under different concentrations of $\mathrm{H}_{2}$ and $\mathrm{CO}_{2}$ test gases in a commercial $\mathrm{N}_{2}$-dry airatmosphere at constant flux and at different temperatures. At each temperature, the system is allowed to stabilize until a constant current flow through the device is achieved (base line). Typical values of current at the sensors range from tens of pA up to a few $\mu \mathrm{A}$ at $1 \mathrm{~V}$ of applied bias. The sensitivity $S$ for a given concentration of the test gas, also labeled as response of the sensor, may be defined as $S=I_{\max } / I_{\min }$, where the subscripts, max and min stand for the maximum and minimum of current through the device, during a pulse of a test gas [41].

Figures 6(a) and 6(b) show, respectively, the response of $\mathrm{TiO}_{2-x}$ nanosensor to three consecutive pulses of $1.7 \% \mathrm{H}_{2}$ and $8 \%$ of $\mathrm{CO}_{2}$ in dry air at different temperatures, namely, $190^{\circ} \mathrm{C}, 215^{\circ} \mathrm{C}$, and $237^{\circ} \mathrm{C}$. Each test gas pulse is $400 \mathrm{~s}$ long, its respective washing time is $800 \mathrm{~s}$ long, and the total gas flux is kept constant. It is easy to see in Figures 6(a) and 6(b) the sensing response of the $\mathrm{TiO}_{2-x}$ to both $\mathrm{H}_{2}$ and $\mathrm{CO}_{2}$ test gases. As expected, in both cases, the response and recovery times decrease as the working temperature increases (a higher temperature accelerates the adsorption and desorption kinetics). The best $\mathrm{TiO}_{2-x}$ sensitivity to $\mathrm{H}_{2}$ is achieved at $215^{\circ} \mathrm{C}$ (Figure $6(\mathrm{a})$ ) and to $\mathrm{CO}_{2}$ at $237^{\circ} \mathrm{C}$ (Figure 6(b)). The reproducibility of the $\mathrm{H}_{2}$ sensor response in the three consecutive pulses and recovering the baseline (initial current) after pulses should be also noted. On the other hand, the $\mathrm{TiO}_{2-x}$ sensor response to $\mathrm{CO}_{2}$ presents a different form in the first test pulse, suggesting some modifications after this initial contact with the working atmosphere, and, in the end of the three pulses, the baseline current is not fully recovered. Nevertheless, in the last two gas pulses, a better reproducibility is observed, suggesting that a pretreatment in the working atmosphere may provide a better reproducibility. $\mathrm{TiO}_{2-x}$ is an $\mathrm{n}$-type semiconductor due to the presence of oxygen vacancies in its structure which creates donor states near the conduction band [43]. Therefore, $\mathrm{TiO}_{2-x}$ increases its conductivity in a reducing atmosphere, such as $\mathrm{H}_{2}$, since the reducing molecule creates more oxygen vacancies at surface of the oxide $[1,4,5,22]$. Although $\mathrm{CO}_{2}$ is neither reducing nor oxidizing, it has molecular orbitals that are mostly localized on oxygen centers. These orbitals 


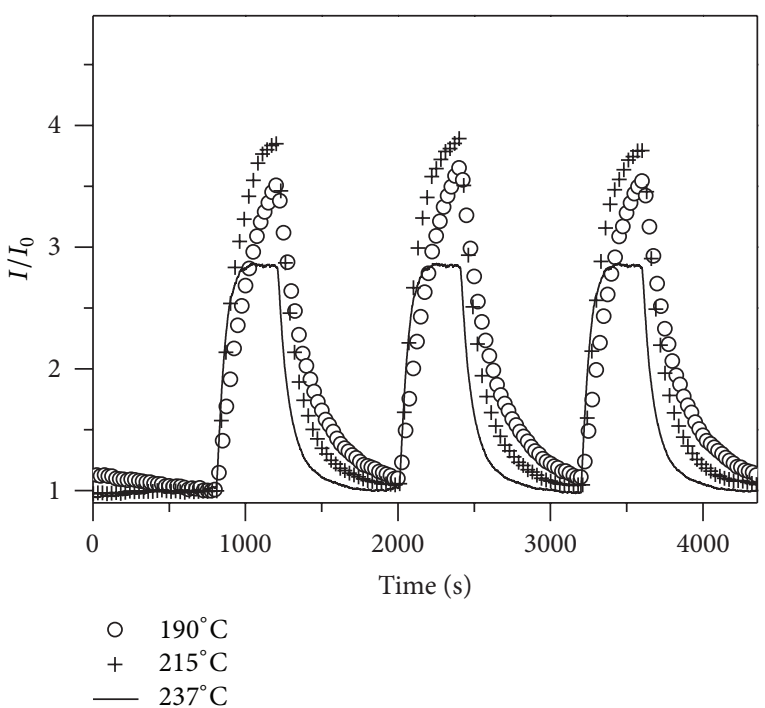

(a)

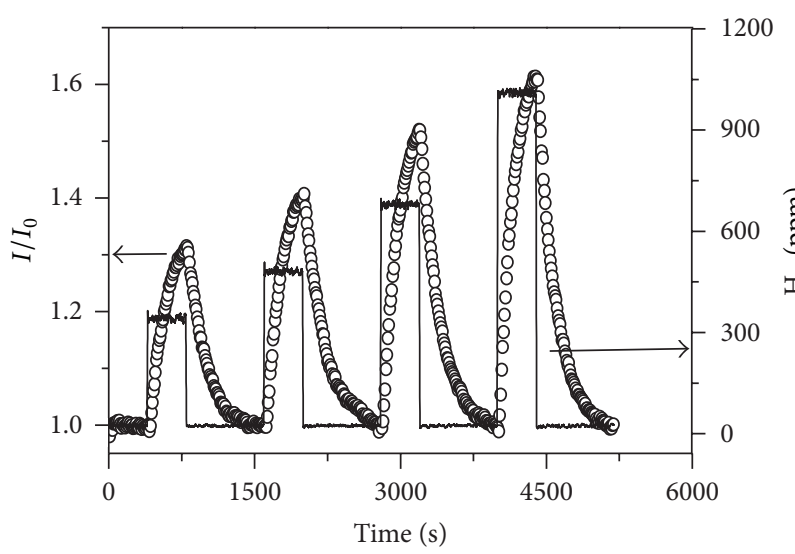

(c)

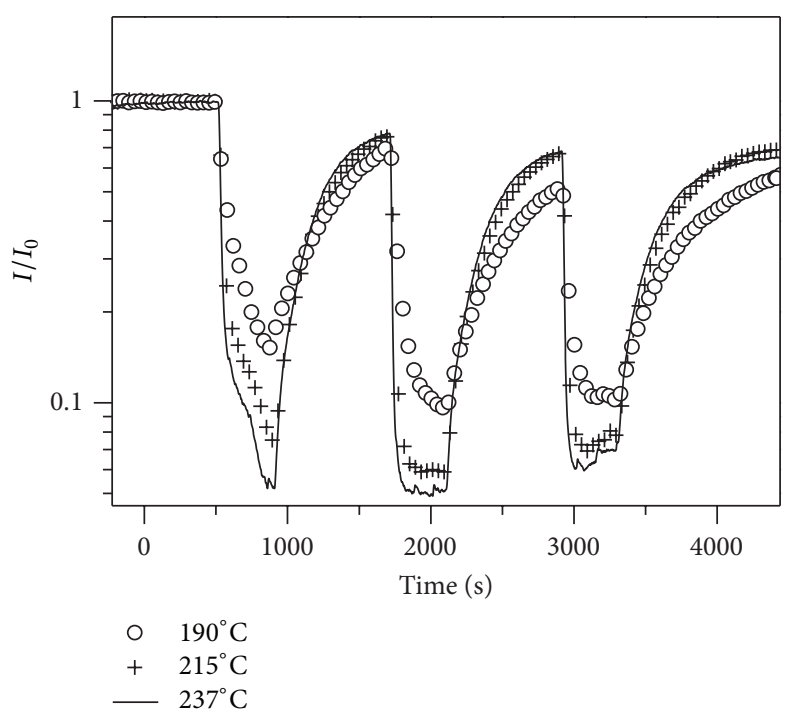

(b)

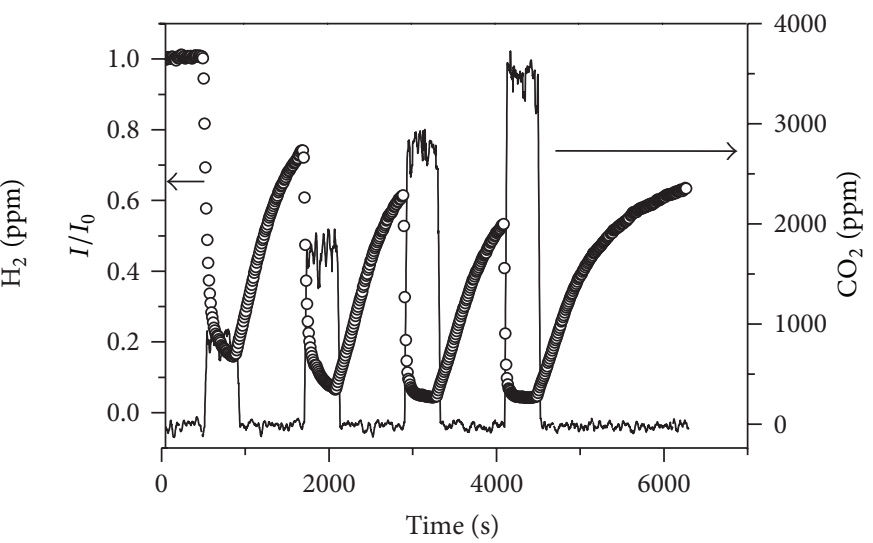

(d)

Figure 6: Normalized current sensing response of the $\mathrm{TiO}_{2-x}$ nanosensor to test gases in dry air. (a) and (b) show, respectively, tests to three consecutive pulses of $1.7 \%$ of $\mathrm{H}_{2}$ and $8 \% \mathrm{CO}_{2}$, at three different temperatures $\left(190^{\circ} \mathrm{C}\right.$-open circles, $215^{\circ} \mathrm{C}-$ crosses, and $237^{\circ} \mathrm{C}-$ continuous line). The sensing response (open circles) to ppm concentration (continuous line) of $\mathrm{H}_{2}$, and $\mathrm{CO}_{2}$ test gases at working temperature of $220^{\circ} \mathrm{C}$ are also shown in (c) and (d), respectively.

overlap with orbitals containing the valence-band electrons of the semiconductor, dropping its conductivity [50].

$\mathrm{TiO}_{2-x}$ sensor sensitivity was tested to ppm levels of $\mathrm{H}_{2}$ and $\mathrm{CO}_{2}$ in dry air. Figures 6(c) and 6(d) show $\mathrm{TiO}_{2-x}$ sensing capabilities to such low amounts of these test gases. The significant sensitivity (1.3), which is obtained even for the lowest $\mathrm{H}_{2}$ concentration used in this work ( $360 \mathrm{ppm}$ ) and its increasing with $\mathrm{H}_{2}$ concentration (a necessary feature for practical applications) is worth noting. Though $\mathrm{TiO}_{2-x}$ sensor presents approximately 1.6 sensitivity to $1000 \mathrm{ppm}$ of $\mathrm{CO}_{2}$ in dry air (Figure 6(d)), the baseline current is not reached after the test, suggesting that better stability and durability must be accomplished.

A comparison between the sensitivities of $\mathrm{TiO}_{2-x}$ nanosensor and microsensor under the same conditions was performed. Therefore, $\mathrm{TiO}_{2-x}$ nanosensors and microsensors were fabricated using both of the oxidation processes described above (Figure 1). Figure 7 shows a direct comparison between a $\mathrm{TiO}_{2-x}$ nanosensor and microsensor, and it is noticeable that the response curve of $\mathrm{TiO}_{2-x}$ sensors has a strong dependence on their size scale. An almost tenfold increase in sensor sensitivity is observed when the sensor size is decreased from the microscale to the nanoscale. A probable explanation arises when a given sensor can be viewed as a set of series resistors. Therefore, the total sensor resistance is a series of association between the resistance related to the semiconductor-metal interface and the resistance associated to the semiconductor (oxide) surface. Hence, the current flow through the device is controlled by both resistors. Since the interface resistance is approximately size independent and the surface resistance increases as the device size increases, it is intuitive to see that the total value of resistance in nanosensor (microsensor) comes almost from the interface (oxide surface). Now, supposing that, for the $\mathrm{TiO}_{2-x}$ case, 


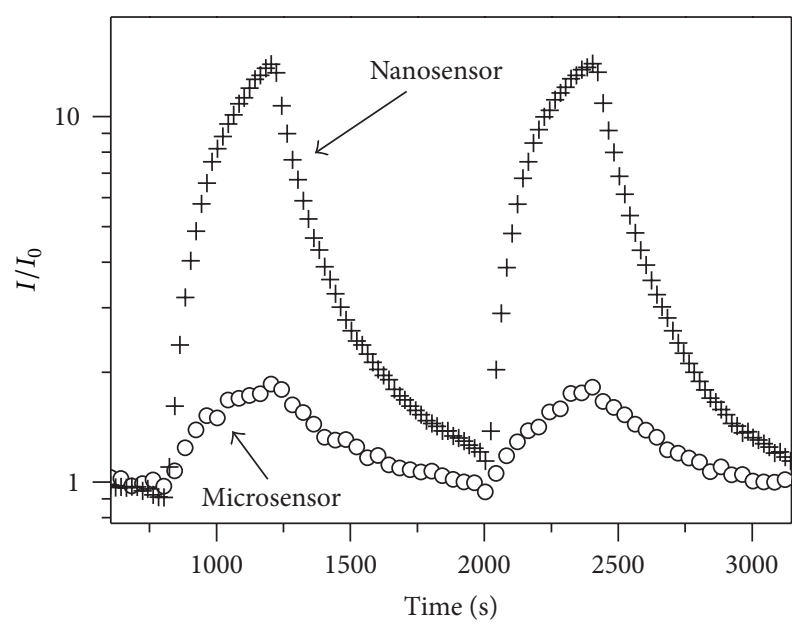

FIgURE 7: Normalized current sensing response of the $\mathrm{TiO}_{2-x}$ nanosensor (crosses) and microsensor (open circles) to $1.5 \% \mathrm{H}_{2}$ concentration in dry air at $190^{\circ} \mathrm{C}$. Both the nanosensor and the microsensor are respectively shown in Figures 1(h) and 1(f).

the interface shows a large resistance variation upon gas exposure, whereas the oxide surface resistance presents a much smaller variation; then, a better sensitivity in a $\mathrm{TiO}_{2-x}$ nanosensor is expected than in $\mathrm{TiO}_{2-x}$ microsensor. Consequently, the results of Figure 7 indicate that the sensitivity in $\mathrm{Ti} / \mathrm{TiO}_{2-x}$ systems comes mostly from the metalsemiconductor interface [41]. Therefore, regarding our best $\mathrm{TiO}_{2-x}$ nanosensor, we obtained a detection range from $360 \mathrm{ppm}$ up to $17000 \mathrm{ppm}(1.7 \%)$ of $\mathrm{H}_{2}$, where the sensitivity varied from 1.3 for $360 \mathrm{ppm}$ up to 13 for $17000 \mathrm{ppm}$. For the same nanosensor, we obtained a detection range for $\mathrm{CO}_{2}$ from $1000 \mathrm{ppm}$ up to $80000 \mathrm{ppm}(8 \%)$, and the sensitivity varied from 3.5 for $1000 \mathrm{ppm}$ up to 13 for $80000 \mathrm{ppm}$. In order to compare the results obtained in this work to the ones present in the literature, we found titanium oxides with the active regions ranging from a few nanometer up to millimeter in extension. Regarding sensor sensitivities, we found it varying from 8 up to 70 when in a few hundreds of $\mathrm{H}_{2}$ ppm in dry air or pure $\mathrm{N}_{2}$. Therefore we notice that the Titanium oxide nanosensor proposed here have similar sensitivities when compared to the state-of-the-art results in the literature [51-54].

Figure 8 shows further electrical characterization of $\mathrm{TiO}_{2-x}$. In Figure 8(a), $I(V)$ curves of $\mathrm{a} \mathrm{TiO}_{2-x}$ nanosensor collected at room temperature, in a $50 \%$ relative humidity (continuous line) and dry atmosphere (open circles multiplied by 10), are plotted together. For visualization purposes, the current through the device in dry air is multiplied by 10 . In other words, $\mathrm{TiO}_{2-x}$ nanosensor has a smaller resistance in dry air, what assures that this device has a considerable sensitivity to humidity even at room temperature. This increase of the electrical conduction of $\mathrm{TiO}_{2-x}$ with atmosphere humidity is due to the water molecules adsorbed at oxide surface that enhance electrolytic conduction as well as protonic conduction [55].

The Arrhenius plots $(I(1 / T))[1,42]$ were performed in order to investigate the electrical conduction process in the
$\mathrm{Ti} / \mathrm{TiO}_{2-x} / \mathrm{Ti}$ barrier and also estimate its activation energy. Figure 8(b) shows, in red, the Arrhenius plot during barrier warming up and, in black, the curve that was collected during system cool down. When the system is warming up, the sensor current remains almost unchanged until $150^{\circ} \mathrm{C}$ (arrow indicating), and, at higher temperatures, current starts to increase very quickly, suggesting that some modifications are taking place at the oxide structure. Actually, we believe that $\mathrm{OH}^{-}$starts to desorb at the oxide surface, increasing the amount of oxygen vacancies and, thus, creating donor levels near the conduction band. Such effect has already been observed in the literature for $\mathrm{WO}_{3}$ sensor systems [56]. The measured activation energy, when the oxide barrier is cooled down, is around $0.3 \mathrm{eV}$, suggesting that it is associated to the depth of donor estates (oxygen vacancies) in the $\mathrm{TiO}_{2-x}$ structures, as also reported in [42].

Differently from $\mathrm{LAO} \mathrm{TiO}_{2-x}$ nanosensors, $\mathrm{LAO} \mathrm{MoO}_{3}$ nanosensors are not stable enough to keep their original dimensions after some working cycles in the scale of minutes. As already point out in this work, Mo oxidizes during LAO process using lower bias voltages than $\mathrm{Ti}$; hence, Mo oxidizes with lower electric fields. Therefore, when a bias voltage is applied between the terminals of the $\mathrm{Mo} / \mathrm{MoO}_{3} / \mathrm{Mo}$ barrier, the electric field is strong enough to continue the oxidation process, increasing the $\mathrm{MoO}_{3}$ line width. As an example, Figures 9(a) and 9(b) show a three-line $\mathrm{MoO}_{3}$ nanosensor before and after applying $1 \mathrm{~V}$ bias in a dry atmosphere at room temperature, respectively; the middle line width increased from $50 \mathrm{~nm}$ up to $250 \mathrm{~nm}$, evidencing the continuation of the oxidation process during an operation cycle. Some experiments were also performed in a 50\% relative humidity atmosphere, and no current flow through the device is measured, as the width increased towards much larger values, also increasing the sensor total electrical resistance. Even with such difficulties, sensitivity responses between $\mathrm{MoO}_{3}$ microsensor and nanosensor were compared, and the variation response seems to be governed by the oxide surface resistance. Therefore, as the sensor size increases, from nanoscale to microscale, no relative sensitivity variation is observed.

Even though $\mathrm{MoO}_{3}$ nanosensors are not stable enough for many working cycles, and also $\mathrm{MoO}_{3}$ microsensors can be used only in dry atmospheres. Hence, Figures 10(a) and 10(b), respectively, show the response of $\mathrm{a} \mathrm{MoO}_{3}$ microsensor to consecutive pulses of $1.7 \% \mathrm{H}_{2}$ and $8 \% \mathrm{CO}_{2}$ in dry air at different temperatures, namely, $237^{\circ} \mathrm{C}, 191^{\circ} \mathrm{C}$, and $145^{\circ} \mathrm{C}$ for $\mathrm{H}_{2}$ (Figure $10(\mathrm{a})$ ) and $329^{\circ} \mathrm{C}, 284^{\circ} \mathrm{C}$, and $237^{\circ} \mathrm{C}$ for $\mathrm{MoO}_{3}$ (Figure $10(\mathrm{~b})$ ). The $\mathrm{MoO}_{3}$ microsensor revealed a poor sensitivity to $\mathrm{H}_{2}(<1.03)$, which decreases as the working temperature increases. On the other hand, it presents a reasonable sensitivity to $\mathrm{CO}_{2}$, around 1.7 at $237^{\circ} \mathrm{C}$. As a result, $\mathrm{MoO}_{3}$ is selective to $\mathrm{CO}_{2}$, compared to $\mathrm{H}_{2}$, in a dry atmosphere. Nevertheless, $\mathrm{MoO}_{3}$ does not recover the baseline current after exposure to $\mathrm{CO}_{2}$, as $\mathrm{TiO}_{2-x}$ does, and also the first $\mathrm{MoO}_{3}$ response to $\mathrm{CO}_{2}$ presents a different form from the subsequent responses. In order to compare the results obtained in this work to the ones present in the literature, we found one recent work using molybdenum oxide with the active regions having few millimeter, of interdigitated finger pattern contacting a film of microscale high aspect 


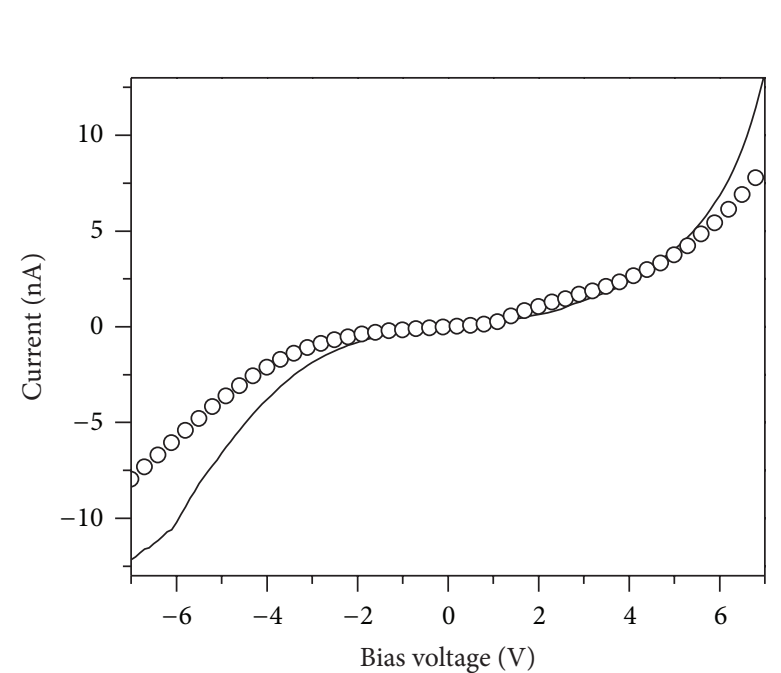

$\bigcirc \times 10$

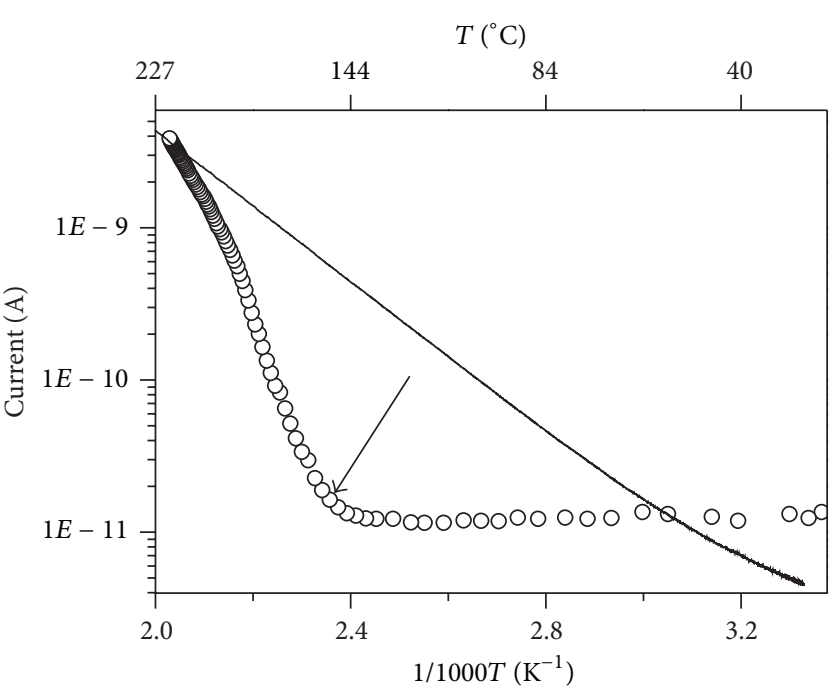

(b)

Figure 8: (a) $I(V)$ curves of an $\mathrm{TiO}_{2-x}$ nanosensor at room temperature in $50 \%$ relative humidity (continuous line) and dry (open circles multiplied by 10) atmospheres. (b) The Arrhenius plot of $\mathrm{TiO}_{2-x}$ nanosenor in warming up (open circles) and cooling down (continuous line).

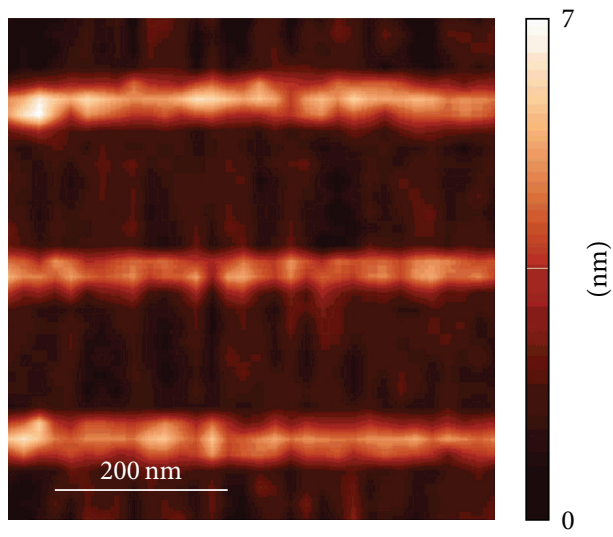

(a)

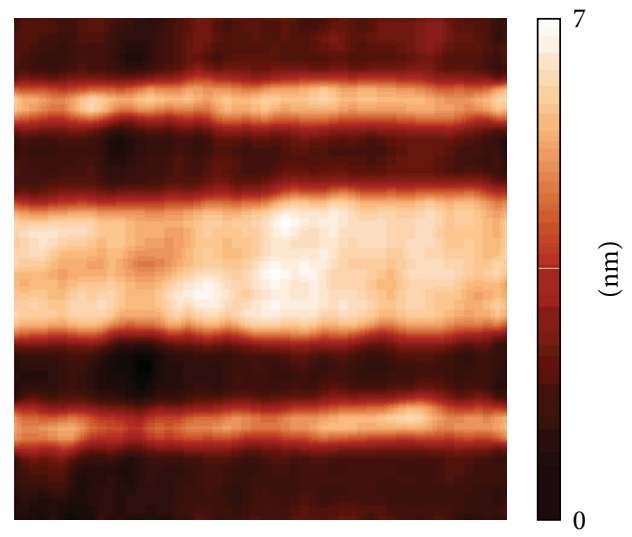

(b)

FIGURE 9: (Color online) AFM topographic images of a $\mathrm{MoO}_{3}$ nanosensor before (a) and after (b) applying $1 \mathrm{~V}$ bias voltage in dry atmosphere at room temperature.

ratio long rectangles. They found sensitivity around 1.4 for $1 \%$ $\mathrm{H}_{2}$ atmosphere in air. Here, again, we show that the molybdenum oxide microsensors proposed in this work have similar sensitivities when compared to the state-of-the-art results in the literature [57].

It should be also noted that the observed responses of $\mathrm{MoO}_{3}$ microsensors to both $\mathrm{H}_{2}$ and $\mathrm{CO}_{2}$ atmospheres cannot be assigned to neither pure n-type nor p-type semiconductor. Actually, these sensors seem to behave as an n-type materials, when in contact with $\mathrm{CO}_{2}$ atmosphere [50], and as p-type material, when in contact with reducing $\mathrm{H}_{2}$ atmosphere, increasing its resistance in both cases. Such behavior is associated to $\mathrm{p}$-n-type transitions, which are reported to occur in $\mathrm{MoO}_{3}$ resistive-type sensors [22].
The Arrhenius plots $[1,42]$ were also generated in order to understand the electrical conduction process in the $\mathrm{Mo} /$ $\mathrm{MoO}_{3} / \mathrm{Mo}$ barrier. Figure 11 shows, in open circles, the Arrhenius plot during microsensor warming up and, in continuous line, the curve that is acquired during system cool down. Since the same behavior is observed with $\mathrm{TiO}_{2-x}$, (current remains almost unchanged until $150^{\circ} \mathrm{C}$-arrow indicating), the modifications at oxide structure seem to be related to the LAO process. The LAO process creates $\mathrm{OH}^{-}$ions, whose bond energies weakly depend on the material being oxidized. The measured activation energy, when the oxide barrier is cooled down, is around $0.4 \mathrm{eV}$, as well as for $\mathrm{TiO}_{2-x}$, suggesting that it is associated to the depth of donor estates (oxygen vacancies) [42] in the $\mathrm{MoO}_{3}$ structures. 


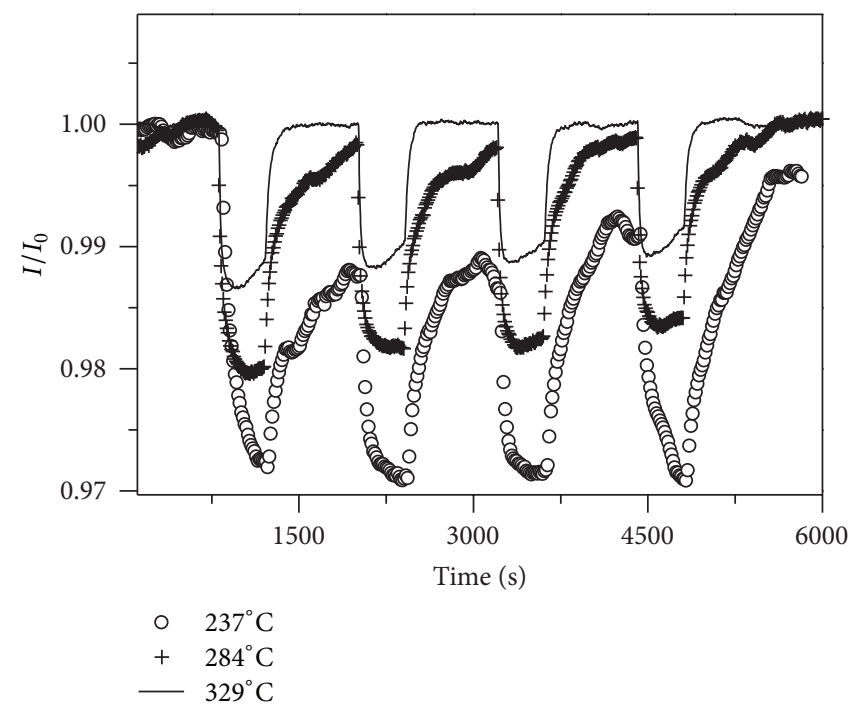

(a)

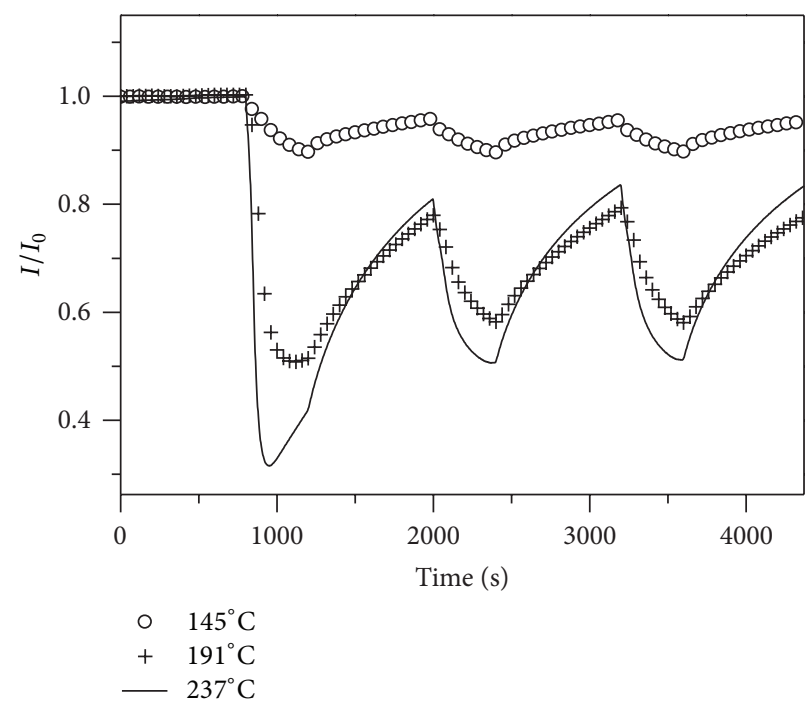

(b)

FIGURE 10: Normalized current sensing response of the $\mathrm{MoO}_{3}$ microsensor to $8 \%$ of $\mathrm{CO}_{2}$ under different temperatures $\left(329^{\circ} \mathrm{C}-\right.$ open circles; $284^{\circ} \mathrm{C}$-crosses; and $237^{\circ} \mathrm{C}$-continuous line) (a) and to $1.7 \%$ of $\mathrm{H}_{2}$ under different temperatures $\left(237^{\circ} \mathrm{C}\right.$-open circles; $191^{\circ} \mathrm{C}-\mathrm{crosses}$ and; and $145^{\circ} \mathrm{C}$-continuous line) (b) test gases in a commercial $\mathrm{N}_{2}$ (dry air).

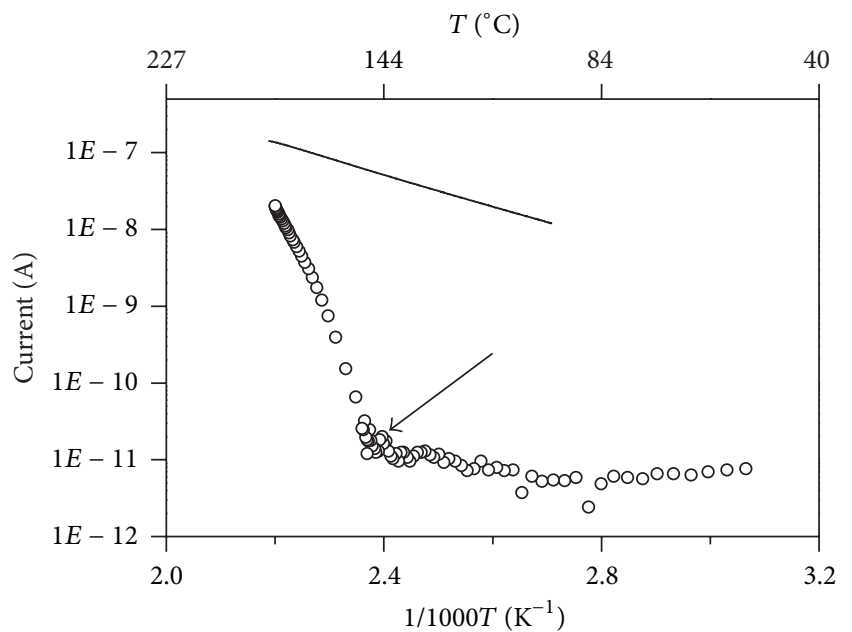

Figure 11: The Arrhenius plot of $\mathrm{MoO}_{3}$ microsensor, warming up and (open circles) and cooling down (continuous line).

In order to further improve the performance of $\mathrm{TiO}_{2-x}$, $\mathrm{MoO}_{3}$ and any order sensor built via LAO process described here, we suggest for future research other procedures such as improving the quality of metal contacts, performing coevaporation of two or more metals, and also performing thermal treatment in different atmospheres depending on the intended application.

\section{Conclusions}

In conclusion, this work further extends a recently proposed methodology of sensor fabrication down to the nanoscale which is based on photolithography and LAO techniques. The sensors presented suitable responses and sensitivities down to low concentrations of test gases, namely, $\mathrm{CO}_{2}$ and $\mathrm{H}_{2}$ in dry air. Furthermore, titanium oxide sensors exhibit a promising use in environmental relative humidity ambients. In principle, this methodology could be applied to any desired metal or metal alloys, as further extending sensing possibilities of nanosensors and microsensors. Using high-resolution TEMrelated techniques, we have characterized the LAO oxide produced here as nanocrystalline $\mathrm{TiO}_{2-x}$ and $\mathrm{MoO}_{3}$.

\section{Conflict of Interests}

The authors declare that there is no conflict of interests regarding the publication of this paper.

\section{Acknowledgments}

The authors acknowledge the financial support from CNPq, Fapemig, Faperj, Finep, Instituto do Milênio de Nanociências e Nanotecnologia/MCT, and CT-Petro/MCT.

\section{References}

[1] M. J. Madou and S. R. Morrison, Chemical Sensing with Solid State Devices, Academic Press, San Diego, Calif, USA, 1989.

[2] E. Comini, V. Guidi, M. Ferroni, and G. Sberveglieri, "Detection of landfill gases by chemoresistive sensors based on titanium, molybdenum, tungsten oxides," IEEE Sensors Journal, vol. 5, no. 1, pp. 4-10, 2005.

[3] A. K. Prasad and P. I. Gouma, " $\mathrm{MoO}_{3}$ and $\mathrm{WO}_{3}$ based thin film conductimetric sensors for automotive applications," Journal of Materials Science, vol. 38, no. 21, pp. 4347-4352, 2003.

[4] W. Göpel and K. D. Schierbaum, " $\mathrm{SnO}_{2}$ sensors: current status and future prospects," Sensors and Actuators B, vol. 26, no. 1-3, pp. 1-12, 1995. 
[5] N. Bârsan and U. Weimar, "Understanding the fundamental principles of metal oxide based gas sensors; the example of $\mathrm{CO}$ sensing with $\mathrm{SnO}_{2}$ sensors in the presence of humidity," Journal of Physics Condensed Matter, vol. 15, no. 20, pp. R813-R839, 2003.

[6] N. Barsan and U. Weimar, "Conduction model of metal oxide gas sensors," Journal of Electroceramics, vol. 7, no. 3, pp. 143-167, 2001.

[7] C. Imawan, F. Solzbacher, H. Steffes, and E. Obermeier, " $\mathrm{TiO}_{\mathrm{x}}{ }^{-}$ modified $\mathrm{NiO}$ thin films for $\mathrm{H}_{2}$ gas sensors: effects of $\mathrm{TiO}_{\mathrm{x}}{ }^{-}$ overlayer sputtering parameters," Sensors and Actuators B, vol. 68, no. 1, pp. 184-188, 2000.

[8] W.-T. Moon, K.-S. Lee, Y.-K. Jun, H.-S. Kim, and S.-H. Hong, "Orientation dependence of gas sensing properties of $\mathrm{TiO}_{2}$ films," Sensors and Actuators B, vol. 115, no. 1, pp. 123-127, 2006.

[9] Y.-K. Jun, H.-S. Kim, J.-H. Lee, and S.-H. Hong, "CO sensing performance in micro-arc oxidized $\mathrm{TiO}_{2}$ films for air quality control," Sensors and Actuators B, vol. 120, no. 1, pp. 69-73, 2006.

[10] C. Garzella, E. Comini, E. Tempesti, C. Frigeri, and G. Sberveglieri, " $\mathrm{TiO}_{2}$ thin films by a novel sol-gel processing for gas sensor applications," Sensors and Actuators B, vol. 68, no. 1-3, pp. 189196, 2000.

[11] D. Manno, G. Micocci, R. Rella, A. Serra, A. Taurino, and A. Tepore, "Titanium oxide thin films for $\mathrm{NH}_{3}$ monitoring: structural and physical characterizations," Journal of Applied Physics, vol. 82, no. 1, pp. 54-59, 1997.

[12] Y. Shimizu, N. Matsunaga, T. Hyodo, and M. Egashira, "Improvement of $\mathrm{SO}_{2}$ sensing properties of $\mathrm{WO}_{3}$ by noble metal loading," Sensors and Actuators B, vol. 77, no. 1-2, pp. 35-40, 2001.

[13] J. L. Solis, A. Hoel, L. B. Kish, C. G. Granqvist, S. Saukko, and V. Lantto, "Gas-sensing properties of nanocrystalline $\mathrm{WO}_{3}$ films made by advanced reactive gas deposition," Journal of the American Ceramic Society, vol. 84, no. 7, pp. 1504-1508, 2001.

[14] M. S. Wagh, G. H. Jain, D. R. Patil, S. A. Patil, and L. A. Patil, "Modified zinc oxide thick film resistors as $\mathrm{NH}_{3}$ gas sensor," Sensors and Actuators B, vol. 115, no. 1, pp. 128-133, 2006.

[15] H. Gong, J. Q. Hu, J. H. Wang, C. H. Ong, and F. R. Zhu, "Nanocrystalline $\mathrm{Cu}$-doped $\mathrm{ZnO}$ thin film gas sensor for CO," Sensors and Actuators B, vol. 115, no. 1, pp. 247-251, 2006.

[16] H. Meixner, J. Gerblinger, U. Lampe, and M. Fleischer, "Thinfilm gas sensors based on semiconducting metal oxides," Sensors and Actuators B, vol. 23, no. 2-3, pp. 119-125, 1995.

[17] S. S. Sunu, E. Prabhu, V. Jayaraman, K. I. Gnanasekar, T. K. Seshagiri, and T. Gnanasekaran, "Electrical conductivity and gas sensing properties of $\mathrm{MoO}_{3}$," Sensors and Actuators B, vol. 101, no. 1-2, pp. 161-174, 2004.

[18] M. Ferroni, V. Guidi, G. Martinelli, P. Nelli, M. Sacerdoti, and G. Sberveglieri, "Characterization of a molybdenum oxide sputtered thin film as a gas sensor," Thin Solid Films, vol. 307, no. 1-2, pp. 148-151, 1997.

[19] S. S. Sunu, E. Prabhu, V. Jayaraman, K. I. Gnanasekar, and T. Gnanasekaran, "Gas sensing properties of PLD made $\mathrm{MoO}_{3}$ films," Sensors and Actuators B, vol. 94, no. 2, pp. 189-196, 2003.

[20] I. Hotovy, J. Huran, P. Siciliano, S. Capone, L. Spiess, and V. Rehacek, "Enhancement of $\mathrm{H}_{2}$ sensing properties of NiO-based thin films with a Pt surface modification," Sensors and Actuators B, vol. 103, no. 1-2, pp. 300-311, 2004.

[21] N. D. M. Sin, M. F. Kamel, R. I. Alip, Z. Mohamad, and M. Rusop, "The electrical characteristics of aluminium doped zinc oxide thin film for humidity sensor applications," Advances in
Materials Science and Engineering, vol. 2011, Article ID 974906, 5 pages, 2011.

[22] A. K. Prasad, D. J. Kubinski, and P. I. Gouma, "Comparison of sol-gel and ion beam deposited $\mathrm{MoO}_{3}$ thin film gas sensors for selective ammonia detection," Sensors and Actuators B, vol. 93, no. 1-3, pp. 25-30, 2003.

[23] D. Zhang, Z. Liu, C. Li et al., "Detection of $\mathrm{NO}_{2}$ down to ppb levels using individual and multiple $\mathrm{In}_{2} \mathrm{O}_{3}$ nanowire devices," Nano Letters, vol. 4, no. 10, pp. 1919-1924, 2004.

[24] A. Kolmakov, D. O. Klenov, Y. Lilach, S. Stemmer, and M. Moskovitst, "Enhanced gas sensing by individual $\mathrm{SnO}_{2}$ nanowires and nanobelts functionalized with Pd catalyst particles," Nano Letters, vol. 5, no. 4, pp. 667-673, 2005.

[25] V. V. Sysoev, B. K. Button, K. Wepsiec, S. Dmitriev, and A. Kolmakov, "Toward the nanoscopic "electronic nose": hydrogen vs carbon monoxide discrimination with an array of individual metal oxide nano- and mesowire sensors," Nano Letters, vol. 6, no. 8, pp. 1584-1588, 2006.

[26] I.-D. Kim, A. Rothschild, B. H. Lee, D. Y. Kim, S. M. Jo, and H. L. Tuller, "Ultrasensitive chemiresistors based on electrospun $\mathrm{TiO}_{2}$ nanofibers," Nano Letters, vol. 6, no. 9, pp. 2009-2013, 2006.

[27] F. Hernández-Ramírez, J. Rodríguez, O. Casals et al., "Characterization of metal-oxide nanosensors fabricated with focused ion beam (FIB)," Sensors and Actuators B, vol. 118, no. 1-2, pp. 198-203, 2006.

[28] N. S. Ramgir, Y. Yang, and M. Zacharias, "Nanowire-based sensors," Small, vol. 6, no. 16, pp. 1705-1722, 2010.

[29] J. Tamaki, A. Miyaji, J. Makinodan, S. Ogura, and S. Konishi, "Effect of micro-gap electrode on detection of dilute $\mathrm{NO}_{2}$ using $\mathrm{WO}_{3}$ thin film microsensors," Sensors and Actuators B, vol. 108, no. 1-2, pp. 202-206, 2005.

[30] J. Tamaki, J. Niimi, S. Ogura, and S. Konishi, "Effect of microgap electrode on sensing properties to dilute chlorine gas of indium oxide thin film microsensors," Sensors and Actuators B, vol. 117, no. 2, pp. 353-358, 2006.

[31] J. Tamaki, Y. Nakataya, and S. Konishi, "Micro gap effect on dilute $\mathrm{H}_{2} \mathrm{~S}$ sensing properties of $\mathrm{SnO}_{2}$ thin film microsensors," Sensors and Actuators B, vol. 130, no. 1, pp. 400-404, 2008.

[32] J. S. Fragala, R. R. Shile, and J. Haaheim, "Enabling the desktop nanofab with DPN pen and ink delivery systems," MRS Proceedings, vol. 1037, 2007.

[33] J. A. Dagata, J. Schneir, H. H. Harary, C. J. Evans, M. T. Postek, and J. Bennett, "Modification of hydrogen-passivated silicon by a scanning tunneling microscope operating in air," Applied Physics Letters, vol. 56, no. 20, pp. 2001-2003, 1990.

[34] H. C. Day and D. R. Allee, "Selective area oxidation of silicon with a scanning force microscope," Applied Physics Letters, vol. 62, no. 21, pp. 2691-2693, 1993.

[35] E. S. Snow and P. M. Campbell, "AFM fabrication of sub-10nanometer metal-oxide devices with in situ control of electrical properties," Science, vol. 270, no. 5242, pp. 1639-1641, 1995.

[36] K. Matsumoto, M. Ishii, K. Segawa, Y. Oka, B. J. Vartanian, and J. S. Harris, "Room temperature operation of a single electron transistor made by the scanning tunneling microscope nanooxidation process for the $\mathrm{TiO}_{x} / \mathrm{Ti}$ system," Applied Physics Letters, vol. 68, no. 1, pp. 34-36, 1996.

[37] A. Fuhrer, S. Lüscher, T. Ihn et al., "Energy spectra of quantum rings," Nature, vol. 413, no. 6858, pp. 822-825, 2001.

[38] C. Delacour, J. Claudon, J.-P. Poizat et al., "Superconducting single photon detectors made by local oxidation with an atomic 
force microscope," Applied Physics Letters, vol. 90, no. 19, Article ID 191116, 2007.

[39] P. F. Siles, B. S. Archanjo, D. L. Baptista et al., "Nanoscale lateral switchable rectifiers fabricated by local anodic oxidation," Journal of Applied Physics, vol. 110, no. 2, Article ID 024511, 2011.

[40] Z. Li, M. Wu, T. Liu, C. Wu, Z. Jiao, and B. Zhao, "Preparation of $\mathrm{TiO}_{2}$ nanowire gas nanosensor by AFM anode oxidation," Ultramicroscopy, vol. 108, no. 10, pp. 1334-1337, 2008.

[41] B. S. Archanjo, G. V. Silveira, A.-M. B. Goncalves et al., "Fabrication of gas nanosensors and microsensors via local anodic oxidation," Langmuir, vol. 25, no. 1, pp. 602-605, 2009.

[42] B. Huber, H. Gnaser, and C. Ziegler, "Electrical properties of nanocrystalline anatase $\mathrm{TiO}_{2}$ thin films with different crystallite size," Surface Science, vol. 566-568, no. 1-3, pp. 419-424, 2004.

[43] F.-C. Chiu, S.-K. Fan, K.-C. Tai, J. Y.-M. Lee, and Y.-C. Chou, "Electrical characterization of tunnel insulator in metal/insulator tunnel transistors fabricated by atomic force microscope," Applied Physics Letters, vol. 87, no. 24, Article ID 243506, 3 pages, 2005.

[44] K. Dengfeng, L. Qinggang, G. Weilian, Z. Shilin, and H. Xiaotang, "Method to detect the property of complex oxide structure formed by AFM anodic oxidation completely," Ultramicroscopy, vol. 105, no. 1-4, pp. 111-114, 2005.

[45] G. Van Der Laan, "Polaronic satellites in x-ray-absorption spectra," Physical Review B, vol. 41, no. 17, pp. 12366-12368, 1990.

[46] G. Bertoni, E. Beyers, J. Verbeeck et al., "Quantification of crystalline and amorphous content in porous $\mathrm{TiO}_{2}$ samples from electron energy loss spectroscopy," Ultramicroscopy, vol. 106, no. 7, pp. 630-635, 2006.

[47] J. P. Strachan, M. D. Pickett, J. J. Yang et al., "Direct identification of the conducting channels in a functioning memristive device," Advanced Materials, vol. 22, no. 32, pp. 3573-3577, 2010.

[48] D. R. Lide, Handbook of Chemistry and Physics, CRC Press, New York, NY, USA, 2006.

[49] D. Wang, D. S. Su, and R. Schlögl, "Electron beam induced transformation of $\mathrm{MoO}_{3}$ to $\mathrm{MoO}_{2}$ and a new phase MoO," Zeitschrift fur Anorganische und Allgemeine Chemie, vol. 630, no. 7, pp. 1007-1014, 2004.

[50] N. G. Patel, K. K. Makhija, and C. J. Panchal, "Fabrication of carbon dioxide gas sensor and its alarm system using indium tin oxide (ITO) thin films," Sensors and Actuators B, vol. 21, no. 3, pp. 193-197, 1994.

[51] M. Guo, X. Xia, Y. Gao, G. Jiang, Q. Deng, and G. Shao, "Selfaligned $\mathrm{TiO}_{2}$ thin films with remarkable hydrogen sensing functionality," Sensors and Actuators B, vol. 171-172, pp. 165-171, 2012.

[52] C. Lu and Z. Chen, "High-temperature resistive hydrogen sensor based on thin nanoporous rutile $\mathrm{TiO}_{2}$ film on anodic aluminum oxide," Sensors and Actuators B, vol. 140, no. 1, pp. 109-115, 2009.

[53] C. S. Rout, G. U. Kulkarni, and C. N. R. Rao, "Room temperature hydrogen and hydrocarbon sensors based on single nanowires of metal oxides," Journal of Physics D, vol. 40, no. 9, article 016, pp. 2777-2782, 2007.

[54] J. Lee, D. H. Kim, S.-H. Hong, and J. Y. Jho, "A hydrogen gas sensor employing vertically aligned $\mathrm{TiO}_{2}$ nanotube arrays prepared by template-assisted method," Sensors and Actuators B, vol. 160, no. 1, pp. 1494-1498, 2011.

[55] W.-P. Tai and J.-H. Oh, "Fabrication and humidity sensing properties of nanostructured $\mathrm{TiO}_{2}-\mathrm{SnO}_{2}$ thin films," Sensors and Actuators B, vol. 85, no. 1-2, pp. 154-157, 2002.
[56] M. Gillet, C. Lemire, E. Gillet, and K. Aguir, "The role of surface oxygen vacancies upon $\mathrm{WO}_{3}$ conductivity," Surface Science, vol. 532-535, pp. 519-525, 2003.

[57] M. B. Rahmani, S. H. Keshmiri, J. Yu et al., "Gas sensing properties of thermally evaporated lamellar $\mathrm{MoO}_{3}$," Sensors and Actuators B, vol. 145, no. 1, pp. 13-19, 2010. 

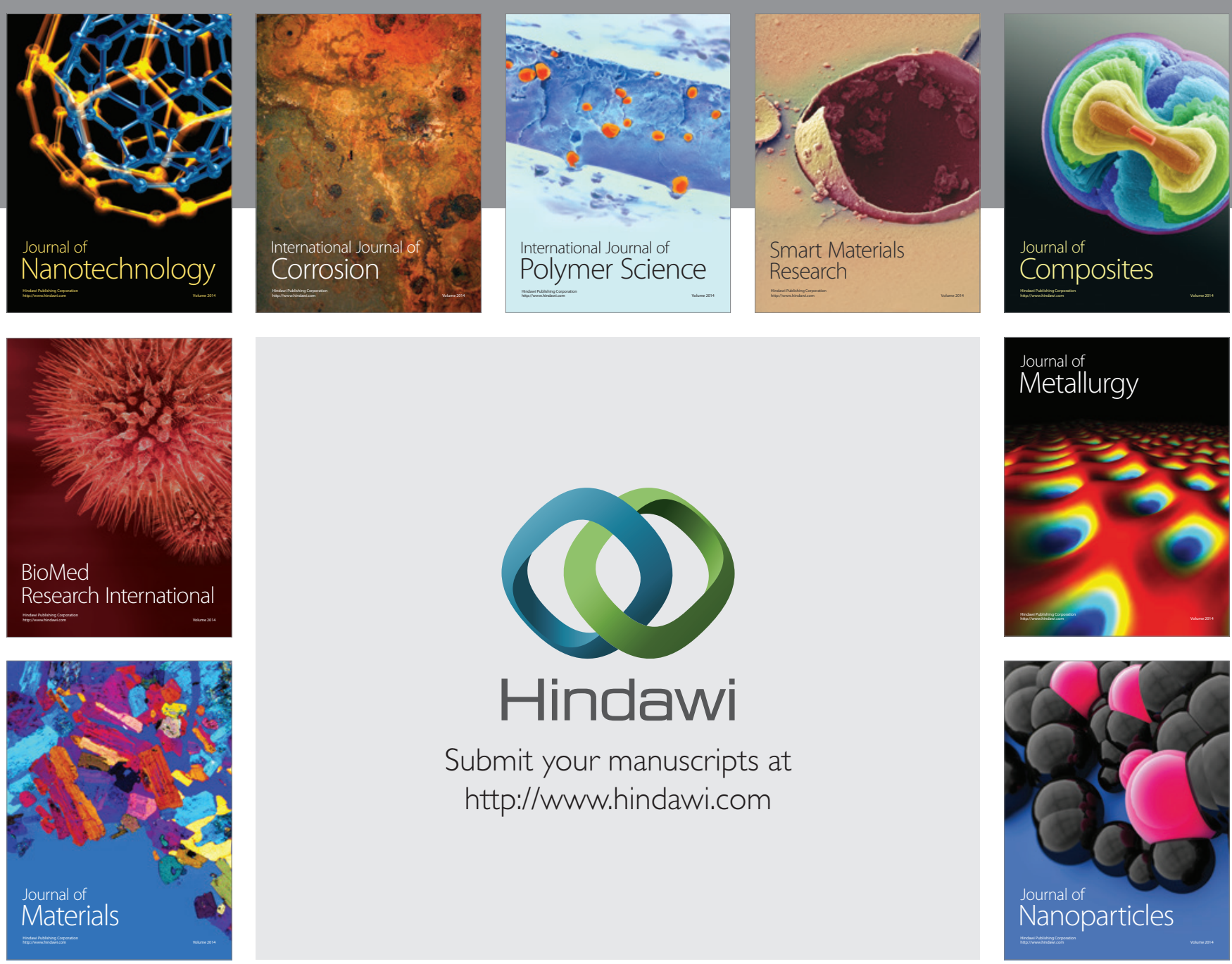

Submit your manuscripts at http://www.hindawi.com
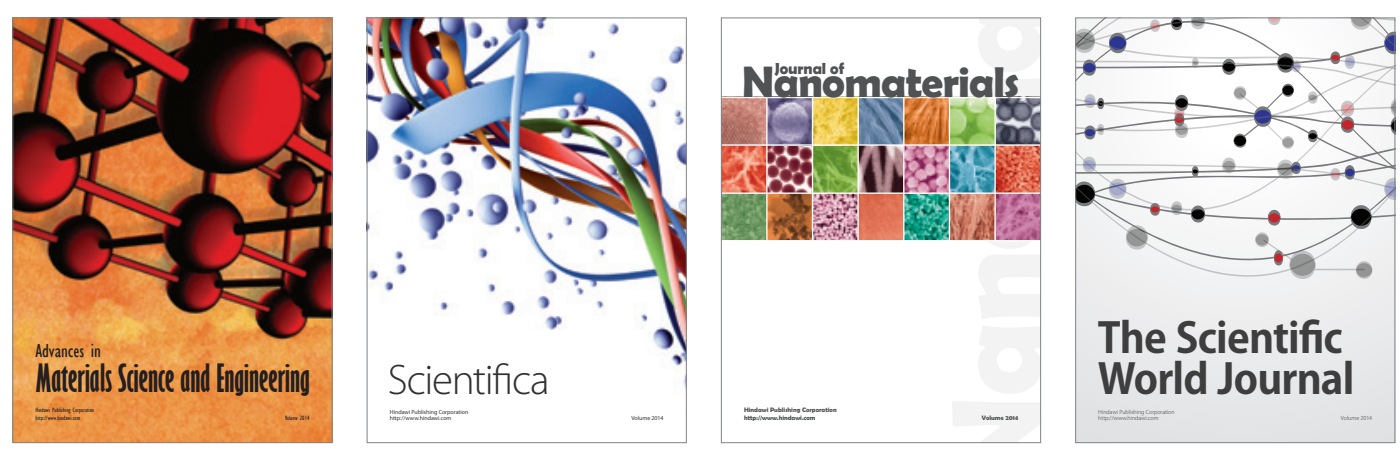

\section{The Scientific World Journal}
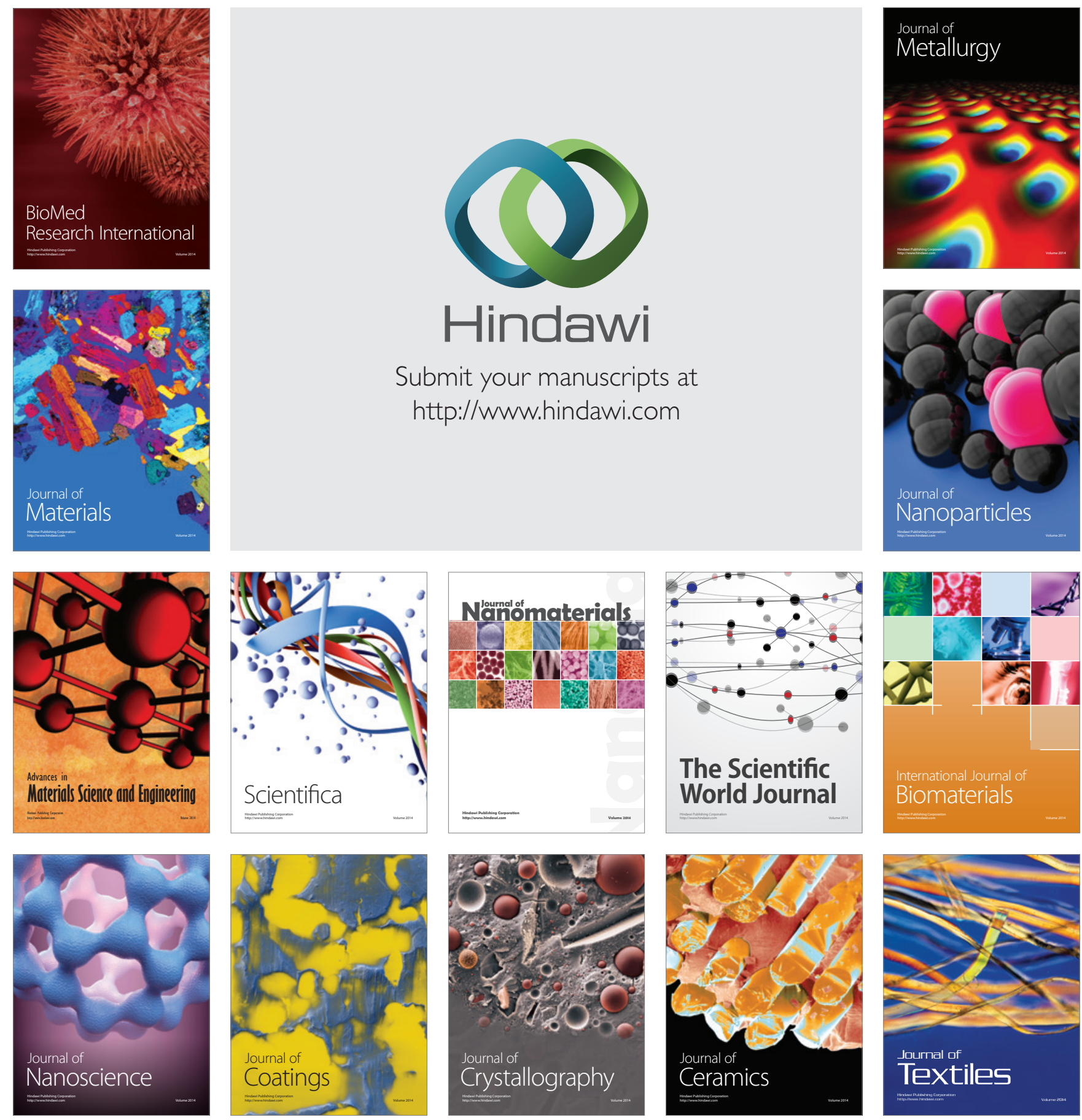